\title{
Assessment of Extrapulmonary Tuberculosis Using Gene Xpert MTB/RIF Assay and Fluorescent Microscopy and Its Risk Factors at Dessie Referral Hospital, Northeast Ethiopia
}

\author{
Yeshi Metaferia (D), Abdurahaman Seid, Genet Mola Fenta, and Daniel Gebretsadik (iD \\ Department of Medical Laboratory Science, College of Medicine and Health Sciences, Wollo University, Ethiopia \\ Correspondence should be addressed to Yeshi Metaferia; metaferiakes@gmail.com
}

Received 24 March 2018; Revised 7 June 2018; Accepted 5 July 2018; Published 7 August 2018

Academic Editor: Frederick D. Quinn

Copyright (C) 2018 Yeshi Metaferia et al. This is an open access article distributed under the Creative Commons Attribution License, which permits unrestricted use, distribution, and reproduction in any medium, provided the original work is properly cited.

\begin{abstract}
Background. Tuberculosis is a major public health problem and extrapulmonary tuberculosis (EPTB) accounts for a significant proportion of tuberculosis cases worldwide. Objective. To determine the magnitude of EPTB, associated risk factors, and agreement of diagnostic techniques at Dessie Referral Hospital. Methods. A cross-sectional study was conducted on consecutive presumptive EPTB cases from March 1 to June 30,2017. Sociodemographic characteristics and other variables were collected using a structured questionnaire. Clinical specimens were collected and processed using fluorescent microscopy and Gene Xpert assay. Data was analyzed using SPSS version 20. Chi-square test and logistic regression were done and a P value of $\leq 0.05$ was taken as statistically significant. Results. From a total of 353 presumptive EPTB cases the overall prevalence of Gene Xpert assay and smear confirmed patients was $8.8 \%$ and $2.5 \%$, respectively. Tuberculosis lymphadenitis was the predominant (33.3\%) type followed by pleural (11.9\%) and peritoneal (6.7\%) tuberculosis. Previous history of pulmonary tuberculosis was significantly associated with extrapulmonary infection (AOR:2.8; 95\%CI: 1.05-7.54; $\mathrm{p}=0.04$ ); however, other variables such as age, residence, sex, marital status, occupation, level of education, and monthly income did not show any association. Conclusion. High proportions (71\%) of Gene Xpert assay confirmed EPTB patients were smear-negative. Sensitivity of microscopy should be enhanced in resource limited countries like Ethiopia where Gene Xpert machine is not easily accessible.
\end{abstract}

\section{Introduction}

Tuberculosis (TB) is a chronic infectious disease and is a major public health problem $[1,2]$. It is the ninth leading cause of death worldwide and the leading cause from a single infectious agent. Globally, according to 2017 World Health Organization (WHO) report, there were an estimated 10.4 million TB cases and 1.6 million TB deaths in 2016 [1], which is much higher than 2013 estimate ( 9.0 million TB cases and 1.5 million TB deaths) [2]. The Majority of TB incident cases occurred in the Southeast Asia Region (45\%) as well as the African (25\%) and Western Pacific Region (17\%). Among the 30 high TB burden countries Ethiopia stands 11th with an estimated TB incidence of 182 per 1000 individuals [1].

Mycobacterium tuberculosis (MTB) usually affects the lungs and causes pulmonary tuberculosis (PTB). Majority of estimated number of incident TB cases were PTB (85\%)
[1]. However, the bacterium can also affect extrapulmonary sites such as lymph nodes, pleura, abdomen (peritoneum and gastrointestinal tract), bones and joints, genitourinary tract, central nervous system, and other multiple organs of the body and resulted in the development of extrapulmonary tuberculosis (EPTB) [3].

According to different reports, the incidence of EPTB has been increasing among TB patients across Ethiopia since the 1990s and recently the estimated numbers of EPTB cases reached $32 \%$ in the country which is higher than other African countries [1]. This is mostly associated with high HIV epidemic in the country [4]. Furthermore, EPTB receives less attention than PTB because of its low infectious potential. The observed diverse manifestations of EPTB may also mimic other pathologies [5] and resulted in more diagnostic challenges, indirectly associated with diagnostic delay and giving it a greater potential for morbidity and mortality [6] 
when compared to PTB. Thus, EPTB deserves an increasing focus for proper management of TB cases and TB control program.

Besides regional variation of WHO report [1] the prevalence of EPTB varies across studies, and it depends on variation of the sociodemographic determinants, geographical location, study population, study designs, method of diagnosis, and rate of human immunodeficiency virus (HIV) coinfection [7]. Among patients with PTB the main determinants of EPTB were male sex, HIV infection, absence of fibrotic lung lesions, smear-negative PTB, anemia, and leukopenia [8]. Female sex, HIV infection, contact history with PTB cases, and low income level were also documented as independent risk factors of EPTB $[9,10]$.

A few cross-sectional studies were conducted among presumptive EPTB cases in Ethiopia for determination of risk factors and prevalence of EPTB which ranged from $9.9 \%$ to $29.8 \%$ [11, 12]. This is higher than other studies conducted elsewhere in the world (2-5\%) [13-15]. Despite variation of EPTB diagnostic techniques, previous studies showed previous history of tuberculosis, contact with known tuberculosis cases, history of underlying chronic diseases, and income level as significant risk factors for EPTB [11, 12]. But, the agreement of the two most recently used TB diagnostic techniques (Gene Xpert MTB/RIF assay and fluorescent microscopy) was not assessed and evaluated. Besides EPTB risk factor analysis, evaluations of commonly used diagnostic tests are suggested among high TB burden countries like Ethiopia where resources are very limited [1]. Hence, this study was designed to determine the magnitude and risk factors of microbiologically confirmed EPTB and to compare diagnostic methods among presumptive EPTB cases in Dessie Referral Hospital, Northeast Ethiopia.

\section{Materials and Methods}

2.1. Study Design and Period. Hospital based cross-sectional study was conducted from March 1 to June 30, 2017.

2.2. Study Setting. The study was conducted at Dessie Referral Hospital which is located at South Wollo, Dessie town, Amhara Region, Northeast Ethiopia. Dessie is located in the Northeastern part of Ethiopia, $401 \mathrm{~km}$ from the capital city, Addis Ababa. The town's location is $11^{0} 8^{1} \mathrm{~N}$ latitude and $39^{0} 38^{1} \mathrm{E}$ longitude. The hospital serves as a Referral Hospital with more than 300 beds and gives different inpatient and outpatient services to more than 7 million populations in the surrounding area and the adjacent regions.

2.3. Sample Size and Sampling Procedures. The study population comprised all clinically presumptive EPTB cases who visited adult outpatient departments (OPD and inpatient wards of Dessie Referral Hospital during the study period). The minimum representative sample size was determined using the single population proportion formula: $N=z^{2} p(1-$ p)/ $d^{2}$, where $N$ is the number of presumptive EPTB cases; $\mathrm{Z}$ is standard normal distribution value at $95 \% \mathrm{CI}$ which is 1.96 ; $\mathrm{P}$ is the prevalence of EPTB $=29.8 \%$ [12]; $\mathrm{d}$ is the margin of error taken as 5\%. Accordingly, the estimated numbers of participants were 321. However, 353 inpatient and outpatient presumptive EPTB cases who visited the Referral Hospital during the study period were enrolled consecutively.

Presumptive EPTB case is any person who presents with signs and symptoms of EPTB including chronic lymphadenitis and body fluid accumulations like meningitis, pleural effusion, ascites, and others with clinical suspicion of tuberculosis. The definition of EPTB case is based on Ethiopian 2013 Ministry of Health guideline, and defined as TB in organs other than the lungs proven by a bacteriologically positive specimen from an extrapulmonary site. A bacteriologically confirmed case is one from whom a biological specimen is positive by smear microscopy, culture, or WHO-approved rapid diagnostics (such as Xpert MTB/RIF).

Presumptive EPTB cases aged $\geq 18$ years and volunteering to participate were considered for inclusion, but presumptive cases who were critically ill and active pulmonary and extrapulmonary tuberculosis patients who were on anti-TB treatment were excluded from the study.

\subsection{Data Collection and Quality Assurance}

Sociodemographic and Related Data. Pretested structured questionnaire which was first prepared in English and then translated into the local language "Amharic version" was used to collect sociodemographic, lifestyle characteristics, and clinical history of the participants. Trained laboratory technologists working in TB laboratory division of Dessie Referral Hospital were employed as data collector.

Clinical Sample Collection and Processing. A total of three hundred and fifty-three extrapulmonary samples comprising cerebrospinal fluid (CSF) (184), peritoneal fluid (45), pleural fluid (109), and lymph node aspirates (15) were collected. All the samples were received in sterile containers. Fine needle aspirate (FNA) samples were collected by a pathologist, while other body fluid samples were collected by physicians during patient investigations and sent to the TB laboratory for microscopic investigation and Gene Xpert MTB/RIF assay analysis.

Before analysis, each sample was carefully homogenized and partitioned into two parts aseptically inside a biosafety cabinet (BSC). One of the split samples with small amount was used to prepare a smear on new, clean, unscratched frosted glass slide. Smears were fixed and stained with the staining reagents, auramine $\mathrm{O}$ stain $(0.1 \%$ auramine O solution, $0.5 \%$ acid-alcohol, and $0.3 \%$ methylene blue). After drying, stained smears were examined under the lightemitting diode (LED) fluorescent microscopy (Primo Star iLED, Carl Zeiss, Gottingen, Germany) with 200x and 400x magnification for acid fast bacilli (AFB) [16].

For Gene Xpert MTB/RIF assay, one of the split samples with sufficient volume was treated with sample reagent (SR) containing $\mathrm{NaOH}$ and isopropanol as per the manufacturer's instruction [17]. Sample reagent was added in a 2:1 ratio to unprocessed sample in $15 \mathrm{ml}$ falcon tube and the tube was manually agitated twice during a 15-minute incubation period at room temperature. From the treated sample $2 \mathrm{ml}$ was transferred into multichambered plastic 
cartridge preloaded with liquid buffers and lyophilized reagent beads necessary for sample processing, deoxyribonucleic acid (DNA) extraction, and heminested real-time polymerase chain reaction (RT-PCR). The cartridge was loaded into the Xpert machine (GeneXpert ${ }^{\circledR}$ Dx System version 4.4a, Cepheid Company, 904 Caribbean Drive, CA 940889, USA), and an automatic process completes the remaining assay steps. The results were visualized and printable in the view results window.

Quality Assurance. The reliability of the study findings was guaranteed by implementing quality control measures throughout the whole processes of research activity. The questionnaire was pretested before the actual study began to make sure that the questions were appropriate and understandable. The collected data was checked daily for consistency and accuracy. BSC was used during sample preparation including initial homogenization, splitting, and smear preparation to ensure safety and avoid risk of contamination. The appropriateness of FM staining reagents was checked with a known positive and negative smear. Blind reading of the slide was performed by two independent laboratory technologists. Gene Xpert MTB/RIF assay has its own internal quality control system which was used during the investigation process. All laboratory tests were performed using standard operational procedures.

2.5. Data Management and Analysis. Data entry and analysis were made using SPSS version 20.0 statistical software. Descriptive statistics were used for analysis of patient characteristics. Chi-square tests and logistic regression analysis were done to determine the presence of a statistically significant association between explanatory variables and the outcome variable. To identify independently associated factors, multivariate logistic regression model was employed by taking presence of EPTB as an outcome variable. All explanatory variables that were associated with the outcome variable in the bivariate analysis $(\mathrm{P} \leq 0.2)$ were included in the multivariate logistic regression model. Odds Ratio (OR), $\mathrm{p}$ value, and their 95\% Confidence Intervals (CI) were calculated and the result was considered statistically significant at $\mathrm{P} \leq 0.05$.

2.6. Ethical Clearance. The Ethical Review Committee of Wollo University, College of Medicine and Health Sciences, approved the study. A permission and support letter were also obtained from the management committee of Dessie Referral Hospital. Patients signed informed consent form to participate in the study. Information obtained at any course of the study was kept confidential. Positive results were made available to clinicians for decision-making as early as available.

\section{Results}

3.1. Sociodemographic, Lifestyle, and Clinical Characteristics. From a total of 353 presumptive EPTB cases who enrolled during the study period, majority $(52.4 \%)$ were males. The age of the participants ranged from 18 to 77 years with mean of 38.16 years ( $\pm \mathrm{SD}=13.45$ years) and $45.6 \%$ of study participants were in the age ranging from 31 to 50 years. About half $(51.6 \%)$ of study participants were rural dwellers and $60.3 \%$ had a monthly income of less than 1500 Ethiopian birr. The majority (74.2\%) of the study subjects were married and $40.0 \%$ were illiterate. About $61.2 \%$ of study participants had greater than three family members living together in the same room (Table 1).

Almost half of (49\%) study participants had chronic diseases of whom $28.32 \%$ had diabetic mellitus (DM) followed by chronic kidney disease $(21.96 \%)$ and hypertension (19.65\%). However, lower proportion of study participants had previous history of PTB infection (9.1\%) and contact with PTB patients (4.5\%) and have had a habit of cigarette smoking (7.6\%), alcohol drinking (14.7\%), and consumption of raw milk (14.7\%) (Table 2).

3.2. Prevalence of Gene Xpert and LED-FM Confirmed Mycobacterium Infection. Among all presumptive EPTB cases, the most commonly suspected site of infection was meninges $(52.1 \%)$, followed by pleural cavity (30.9\%) as shown in Table 3. The Gene Xpert MTB/RIF assay result showed that 31 out of $353(8.78 \%)$ presumptive EPTB cases were positive for Mycobacterium tuberculosis complex. Of these, $9(2.5 \%)$ were AFB positive using LED-FM staining technique. The Gene Xpert MTB/RIF assay result revealed statistically significant variation among different types of body fluids $(\mathrm{p}=0.001)$, but LED-FM technique did not show any significant variation $(p>0.05)$. Higher discordant results between LED-FM and Gene Xpert MTB/RIF assay were observed. For instance, out of the thirteen Gene Xpert $\mathrm{MTB} / \mathrm{RIF}$ assay positive pleural fluid samples only two were positive for AFB by LED-FM technique as shown in Table 3. Cohen's Kappa was computed to evaluate the agreement between Gene Xpert MTB/RIF assay and LED-FM microscopy. The result showed that the test agreement of the two methods was 0.427 indicating that these two methods do not provide similar results on the diagnosis of EPTB infection.

3.3. Associated Risk Factors of EPTB Infection. In the current study, sociodemographic characteristics such as age, sex, residence, monthly income, family size living together, occupation, and educational level were not significantly associated with EPTB. Furthermore, bivariate analysis also showed that lifestyle characteristics such as cigarette smoking, alcohol drinking, and consumption of raw milk were not significantly associated with EPTB. However, history of previous PTB infection (COR: 2.73 ; 95\%CI: 1.03-7.26) and contact with PTB patients (COR: 3.83; 95\%CI: 1.16-12.68) were significantly associated with EPTB Gene Xpert MTB/RIF assay positivity. On multivariate logistic regression analysis, previous history of PTB (AOR: 2.81; 95\%CI: 1.05-7.54) remains the only predictor of EPTB (Table 4).

\section{Discussion}

Nowadays EPTB is becoming a major concern of tuberculosis control programs. Formerly, it was more prevalent in 
TABLE 1: Sociodemographic characteristics of presumptive EPTB cases at Dessie Referral Hospital, from March 1 to June 30, 2017.

\begin{tabular}{|c|c|c|}
\hline Variable & Frequency & Percent \\
\hline \multicolumn{3}{|l|}{ Age in years } \\
\hline $18-30$ & 132 & 37.4 \\
\hline $31-50$ & 161 & 45.6 \\
\hline$>50$ & 60 & 17.0 \\
\hline \multicolumn{3}{|l|}{ Sex } \\
\hline Male & 185 & 52.4 \\
\hline Female & 168 & 47.6 \\
\hline \multicolumn{3}{|l|}{ Residence } \\
\hline Urban & 171 & 48.4 \\
\hline Rural & 182 & 51.6 \\
\hline \multicolumn{3}{|l|}{ Marital status } \\
\hline Married & 262 & 74.2 \\
\hline Single & 91 & 25.8 \\
\hline \multicolumn{3}{|l|}{ Occupation } \\
\hline House wife & 99 & 28.0 \\
\hline Merchant & 84 & 23.8 \\
\hline Farmer & 93 & 26.3 \\
\hline Others & 77 & 21.8 \\
\hline \multicolumn{3}{|l|}{ Educational Status } \\
\hline Illiterate & 143 & 40.5 \\
\hline Grades 1-8 & 93 & 26.3 \\
\hline Grade 9 \& above & 117 & 33.1 \\
\hline \multicolumn{3}{|l|}{ Monthly income } \\
\hline$\leq 1500$ birr & 213 & 60.3 \\
\hline$>1500$ birr & 140 & 39.7 \\
\hline \multicolumn{3}{|l|}{ Family size } \\
\hline $1-3$ & 137 & 38.8 \\
\hline$>3$ & 216 & 61.2 \\
\hline
\end{tabular}

developed nations than developing countries but these days it has high proportion in developing nations including Ethiopia [1]. Identification of the risk factors that predispose to EPTB would allow designing targeted strategies to prevent active tuberculosis infection and hence decrease the prevalence of EPTB. The current study was conducted among presumptive EPTB cases for determination of EPTB prevalence and risk factors associated with it.

In this study, the most common suspected extrapulmonary sites were meninges, pleural, peritoneal, and lymph nodes in decreasing order. However, TB disease detection rate was highest among patients suspected of having $\mathrm{TB}$ lymphadenitis (33.3\%) followed by pleural effusion (11.9\%) as shown in Table 3. Our result is in line with previous study as TB lymphadenitis is diagnosed among 33.3 to $82.4 \%$ of presumptive EPTB cases in Ethiopia [11,12]. Similarly, studies conducted in other countries showed TB lymphadenitis as the common form of EPTB followed by pleural forms [1820]. Recent reports from Sudan also indicated that TB lymphadenitis is the most frequent form of EPTB followed by peritoneal TB [21]. In contrast, other reports have shown pleural effusion as the most frequent form of EPTB, followed by lymphatic TB $[22,23]$. The reasons for these discrepancies were unknown; however, authors considered pleural TB as an early manifestation of primary mycobacterial infection [24].

In this study the overall prevalence of Gene Xpert MTB/RIF assay positive EPTB cases was $8.8 \%$ which is lower than study conducted in Gondar, Ethiopia (26.2\%) [12]. The low prevalence rate of EPTB in our study cohort might be due to earlier presentation of presumptive cases with more paucibacillary disease, which might result in a decreased sensitivity of Gene Xpert MTB/RIF assay [25]. Furthermore, in our study, the prevalence of smear-positive (LED-FM) EPTB cases was $2.5 \%$ which is lower than the prevalence rate reported in Ethiopia (9.9\%) [11], Nigeria (5\%) [14], and India (3.9\%) [15]. But our smear detection rate is comparable with reports of Patel et al., 2.26\% [13]. The observed difference might be due to variation of healthcare providers' knowledge of EPTB suspicion and diagnosis.

Moreover, it could be attributed to difference in sociodemographic characteristics of study participants and variation in study design or laboratory diagnostic techniques. For instance, studies conducted in Gondar, Ethiopia, utilized culture and concentrated specimens for Gene Xpert MTB/RIF assay [12] and smear microscopy [11], whereas in our study due to lack of infrastructure direct samples were used for 
TABLE 2: Lifestyle and clinical characteristics of presumptive EPTB cases at Dessie Referral Hospital, from March 1 to June 30, 2017.

\begin{tabular}{|c|c|c|}
\hline Variable & Frequency & Percent \\
\hline \multicolumn{3}{|c|}{ Cigarette Smoking } \\
\hline Yes & 27 & 7.6 \\
\hline No & 326 & 92.4 \\
\hline \multicolumn{3}{|c|}{ Alcohol Drinking } \\
\hline Yes & 52 & 14.7 \\
\hline No & 301 & 85.3 \\
\hline \multicolumn{3}{|c|}{ previous PTB infection } \\
\hline Yes & 32 & 9.1 \\
\hline No & 321 & 90.9 \\
\hline \multicolumn{3}{|l|}{ chronic illness } \\
\hline Yes & 173 & 49.0 \\
\hline No & 180 & 51.0 \\
\hline \multicolumn{3}{|c|}{ Type chronic illness $(n=173)$} \\
\hline Kidney & 38 & 21.96 \\
\hline HIV & 32 & 18.49 \\
\hline $\mathrm{DM}$ & 49 & 28.32 \\
\hline Hypertension & 34 & 19.65 \\
\hline Others & 20 & 11.56 \\
\hline \multicolumn{3}{|c|}{ Contact with PTB patients } \\
\hline Yes & 16 & 4.5 \\
\hline No & 337 & 95.5 \\
\hline \multicolumn{3}{|c|}{ Consumption of raw milk } \\
\hline Yes & 52 & 14.7 \\
\hline No & 301 & 85.3 \\
\hline
\end{tabular}

TABLE 3: Prevalence of Gene Xpert MTB/RIF assay and LED-FM confirmed EPTB patients at Dessie Referral Hospital, from March 1 to June 30, 2017.

\begin{tabular}{|c|c|c|c|c|c|c|c|}
\hline \multirow[t]{2}{*}{ Sample type } & \multirow{2}{*}{$\begin{array}{l}\text { Total } \\
\mathbf{n}(\%)\end{array}$} & \multicolumn{2}{|c|}{ Gene Xpert MTB/RIF assay } & \multirow{2}{*}{$\begin{array}{c}\chi^{2} \\
\text { p-value }\end{array}$} & \multicolumn{2}{|c|}{ LED- FM } & \multirow{2}{*}{$\begin{array}{c}\chi^{2} \\
\text { p-value }\end{array}$} \\
\hline & & $\begin{array}{c}\text { Negative } \\
\mathrm{n}(\%)\end{array}$ & $\begin{array}{c}\text { Positive } \\
\mathrm{n}(\%)\end{array}$ & & $\begin{array}{c}\text { positive } \\
\mathrm{n}(\%)\end{array}$ & $\begin{array}{c}\text { negative } \\
\mathrm{n}(\%)\end{array}$ & \\
\hline CSF & $184(52.1)$ & $174(94.6)$ & $10(5.4)$ & $\begin{array}{c}15.457 \\
0.001\end{array}$ & $6(3.3)$ & $178(96.7)$ & $\begin{array}{r}2.799 \\
0.424\end{array}$ \\
\hline Peritoneal fluid & $45(12.7)$ & $42(93.3)$ & $3(6.7)$ & & $0(0)$ & $45(100)$ & \\
\hline Pleural fluid & $109(30.9)$ & $96(88.1)$ & 13(11.9) & & $2(1.8)$ & $107(98.2)$ & \\
\hline LNA & $15(4.3)$ & $10(66.7)$ & $5(33.3)$ & & $1(6.7)$ & $14(93.3)$ & \\
\hline Total & & $322(91.22)$ & $31(8.78)$ & & $9(2.5)$ & $344(97.5)$ & \\
\hline
\end{tabular}

CSF: cerebrospinal fluid; LNA: lymph node aspirate.

Gene Xpert MTB/RIF assay and smear microscopy. In line with this evidence, Tadesse and colleagues demonstrated that bleach concentration and pelleting of smear-negative samples increase Gene Xpert MTB/RIF sensitivity from $63.2 \%$ to $73.8 \%$ [26]. This, in fact, highlights the benefit of concentrating nonrespiratory samples for diagnosis of EPTB using Gene Xpert MTB/RIF assay and microscopy; however, it needs comprehensive and comparative study, particularly in resource limited countries like Ethiopia, to elucidate the long term benefit of nonrespiratory sample concentration for TB patient management.

In our study, Gene Xpert MTB/RIF assay analysis also showed significant variation among nonrespiratory samples to detect Mycobacterium tuberculosis complex $(\mathrm{p}=0.001)$ but no statistical difference was observed using LED-FM (Table 3). The Mycobacterium tuberculosis complex detection rate was $33.3 \%$ for lymph node aspirates and $11.9 \%$ for pleural fluid. It is already documented that Gene Xpert MTB/RIF assay sensitivity differed substantially between sample types. A recent systematic review and meta-analysis showed that Gene Xpert MTB/RIF assay was highly sensitive for TB detection in lymph node samples and moderately sensitive for the detection of TB meningitis ( $83.1 \%$ and $80.5 \%$, respectively), but lower sensitivity was shown (46.4\%) for testing pleural fluid [27].

In our analysis, Gene Xpert MTB/RIF assay and LEDFM did not provide similar results with 0.427 Cohen's Kappa measure of agreement. However, all samples which were 


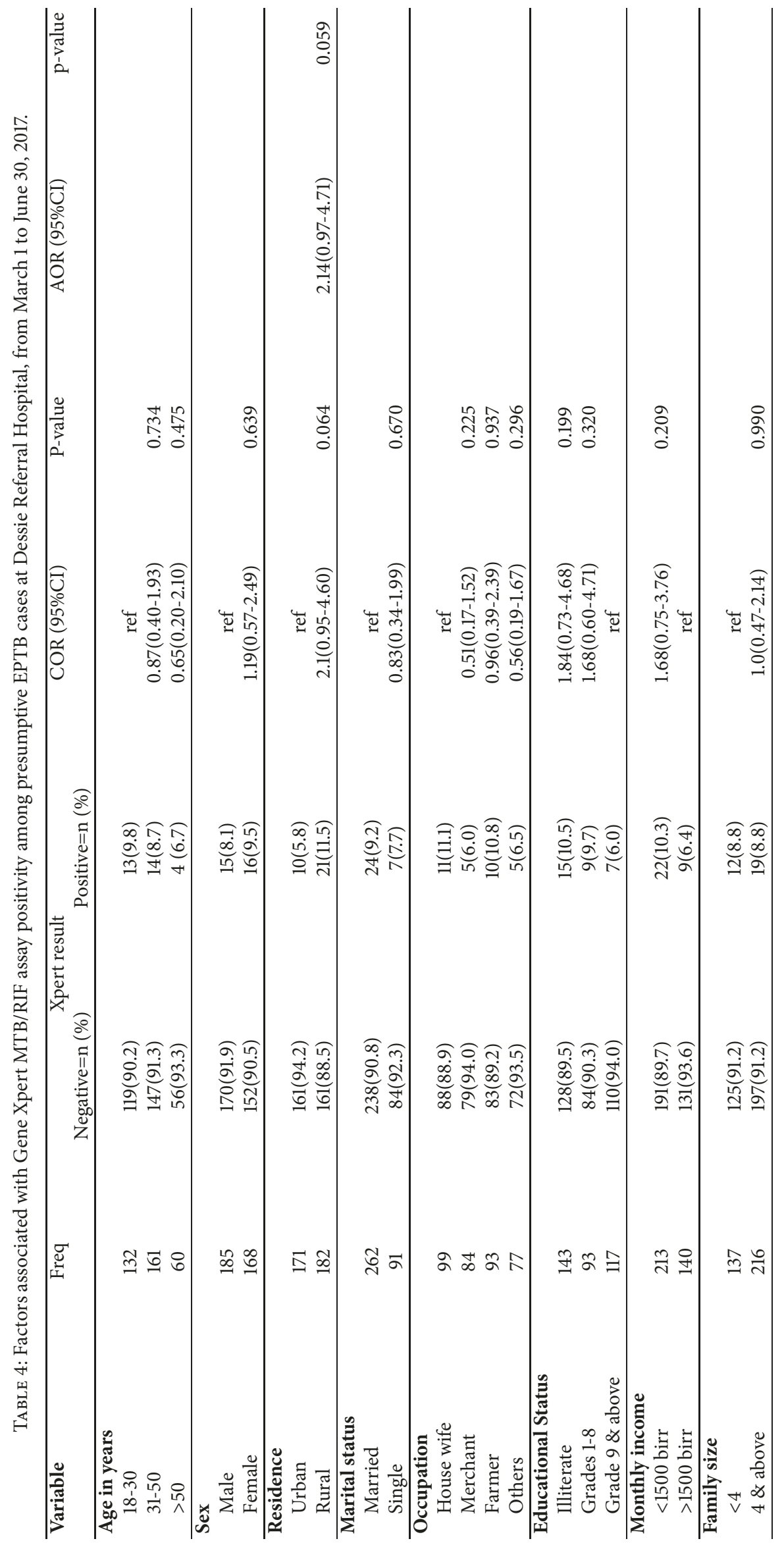




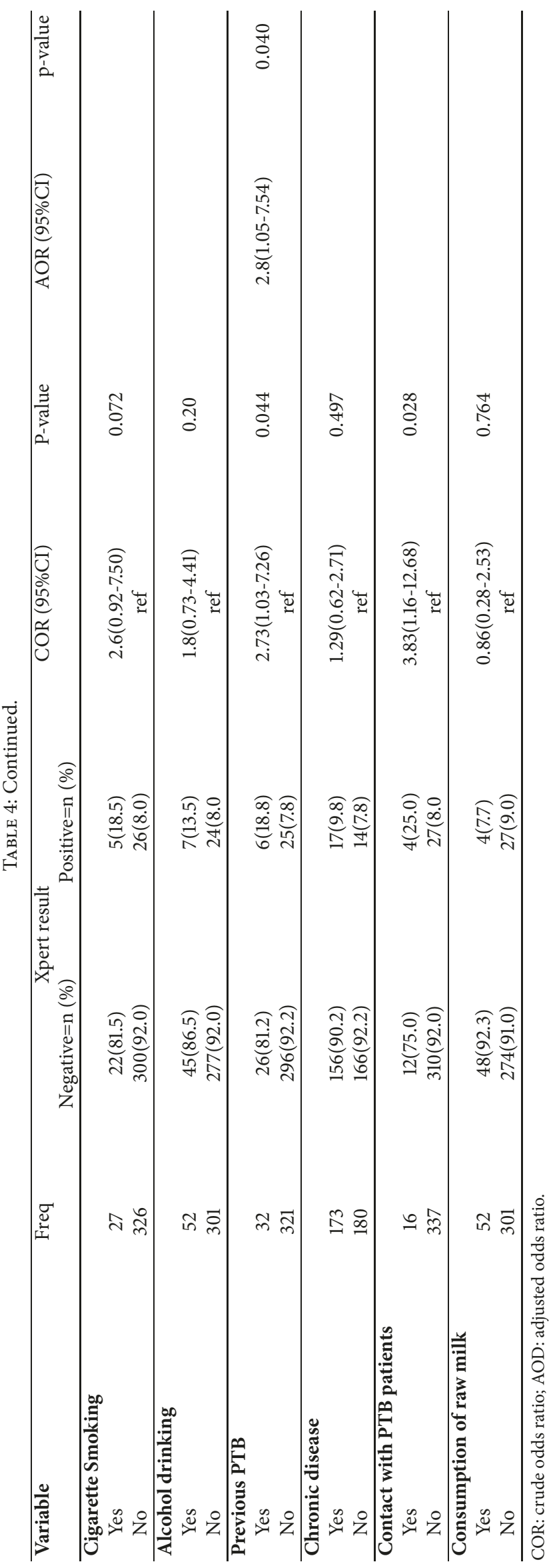


LED-FM smear-positive were also Gene Xpert MTB/RIF assay positive. This is due to the high sensitivity (97.4\%) of Gene Xpert MTB/RIF assay in smear-positive samples across all sample types [25]. Additionally, Bates et al. in their study reported a better detection rate with Gene Xpert MTB/RIF assay when compared to smear microscopy and culture [28], and Xpert MTB/RIF analysis is found to increase the TB detection rate by $47.4 \%$ compared with smear microscopy [29]. Lombardi et al. also showed a 73.1\% Gene Xpert $\mathrm{MTB} / \mathrm{RIF}$ assay sensitivity in smear-negative samples as compared to culture which was independent of specimen origin [30]. A systematic review showed a $66 \%$ performance sensitivity of Gene Xpert MTB/RIF assay for diagnosis of smear-negative nonrespiratory samples [31].

In the current study, the highest proportion (about 71\%) of smear-negative but Gene Xpert MTB/RIF assay positive results could be partially ascribed to performing smear microscopy directly on unprocessed sample. In our cohort, although the performance of smear microscopy was clearly inferior to that of Xpert MTB/RIF, no false positive smear results were observed. In our opinion, Xpert MTB/RIF assay should be considered as an adjunct test for improved case detection in smear-negative EPTB suspects in low income settings like Ethiopia, instead of replacing smear microscopy.

In the current study, sociodemographic characteristics like sex, age, marital status, and occupation were not significantly associated with EPTB infection; similar findings were reported in Gonder, Ethiopia [11]. Additionally, univariate analysis showed that history of contact with pulmonary $\mathrm{TB}$ cases was a significant risk factor for EPTB but if adjusted for other variables it lost its association. The most important risk factor that was significantly associated with EPTB infection in the present study was history of previous PTB infection $(\mathrm{P}=0.04)$ which is similar to previous reports $[9,10]$. A study conducted in Cameron showed that about a quarter of patients with PTB have developed EPTB and both HIV infection and smear-negative PTB emerged as independent predictors of extrapulmonary involvement [8].

Our results also demonstrated that smoking was not associated with EPTB which is consistent with other studies [21] and smoking was reported as the risk factor for PTB compared with EPTB [32]. Similarly, in our study occupation and residence of participants were not associated with EPTB which is in agreement with study conducted in Sudan [21]. In the present study, only two samples demonstrated rifampicin resistant Mycobacterium tuberculosis complex making the prevalence of rifampicin resistant-TB 6.5\% (2/31). Report from Addis Ababa showed a 2.3\% MDR-TB among newly diagnosed EPTB cases [33]. In the Northwestern Ethiopia, the prevalence of MDR-TB among EPTB cases was found to be $3.7 \%$ [34]. Even though the observed frequency of rifampicin resistant case is low, it highlights the need of screening of EPTB patient for MDR-TB.

Our study has some limitations. Firstly, being conducted in hospital might not reflect reality of the community but it gives valuable information on burden of EPTB as well as importance of MDR-TB screening of EPTB cases in the study area. Although HIV infection is known risk factor for increasing EPTB infection, HIV status was not known in substantial number of EPTB suspected cases. However, this is quite important to be investigated with another future research. The present study employed only fluorescence staining technique and Gene Xpert MTB/RIF assay which have generally low sensitivity in comparison with culture, which is the gold standard for detection of EPTB due to paucibacillary nature of specimens and thus may underestimate the prevalence EPTB among the study cohorts.

\section{Conclusions}

The prevalence of Gene Xpert MTB/RIF assay and LEDFM confirmed EPTB was $8.8 \%$ and $2.5 \%$, respectively. The most prevalent type of EPTB was TB lymphadenitis. Sociodemographic characteristics and lifestyle factors did not show significant association with EPTB. However, a previous history of pulmonary tuberculosis infections was significantly associated with Gene Xpert MTB/RIF assay confirmed EPTB. Discordant results were observed between LED-FM and Gene Xpert MTB/RIF assay with 71\% (22/31) of smear-negative EPTB cases being Gene Xpert MTB/RIF assay positive and this needs developing strategies to enhance the sensitivity of FM microscopy for diagnosis of EPTB in resource limited countries like Ethiopia. Moreover, large scale study on the prevalence and risk factor of EPTB infection using culture or other more sensitive methods could help to determine the exact prevalence of EPTB infection in the study area.

\section{Abbreviations \\ MTB: Mycobacterium tuberculosis \\ TB: Tuberculosis \\ EPTB: Extrapulmonary tuberculosis \\ PTB: Pulmonary tuberculosis \\ LED: Light-emitted diode \\ FM: Fluorescent microscope.}

\section{Data Availability}

The data used to support the findings of this study are included within the article.

\section{Disclosure}

The funder had no role in study design, data collection and analysis, decision to publish, or preparation of the manuscript.

\section{Conflicts of Interest}

The authors declare that they have no conflicts of interest.

\section{Authors' Contributions}

Yeshi Metaferia contributed to the design of the study, data acquisition and management, study supervision, analysis, 
interpretation of data, and manuscript preparation. Abdurahaman Seid contributed to study design, supervision, acquisition, analysis and interpretation of data, and manuscript preparation. Genet Molla Fenta contributed to study design, supervision, acquisition of data, and critical review of the manuscript. Daniel Gebretsadik contributed to study design, supervision, and critical review of the manuscript. All authors have edited and approved the final manuscript for publication.

\section{Acknowledgments}

The authors would like to acknowledge Wollo University for the approval of ethical clearance and funding support of this study. They also acknowledge South Wollo Zonal Health Bureau and Dessie Referral Hospital. The authors also express their gratitude to study participants, data collectors, and supervisors who participated in the study.

\section{References}

[1] "Global tuberculosis report," http://www.who.int/tb/publications/global_report/en/, WHO 2017.

[2] "World Health Organization Global Tuberculosis Report 2014, WHO, Geneva, Switzerland," http://apps.who.int/iris/bitstream/handle/10665/137094/9789241564809_eng.pdf;jsession$\mathrm{id}=\mathrm{D} 7 \mathrm{D} 74 \mathrm{AEA5349CDB2D} 35 \mathrm{CC} 4682 \mathrm{E} 2 \mathrm{~F} 0486$ ? sequence $=1$, 2014.

[3] D. W. Fitzgerald, T. R. Sterling, and D. W. Haas, "Mycobacterium tuberculosis," in Mandell, Douglas, and Bennett's Principles and Practice of Infectious Diseases, J. E. Bennett, R. Dolin, and M. J. Blaser, Eds., pp. 2787-2818, Elsevier, Philadelphia, PA, USA, 8th edition, 2015.

[4] B. E. Jones, S. M. M. Young, D. Antoniskis, P. T. Davidson, F. Kramer, and P. F. Barnes, "Relationship of the manifestations of tuberculosis to CD4 cell counts in patients with human immunodeficiency virus infection," American Review of Respiratory Disease, vol. 148, no. 5, pp. 1292-1297, 1993.

[5] H. J. Yoon, Y. G. Song, W. I. Park, J. P. Choi, K. H. Chang, and J. M. Kim, "Clinical manifestations and diagnosis of extrapulmonary tuberculosis," Yonsei Medical Journal, vol. 45, no. 3, p. 453, 2004.

[6] E. L. Tay, "Innovative use of tuberculosis surveillance data to inform practice \& policy," in Presented at Advances in Tuberculosis: Australian and Regional Perspectives, Melbourne, Victoria, 2013.

[7] J. Cailhol, B. Decludt, and D. Che, "Sociodemographic factors that contribute to the development of extrapulmonary tuberculosis were identified," Journal of Clinical Epidemiology, vol. 58, no. 10, pp. 1066-1071, 2005.

[8] E. W. P. Yone, A. P. Kengne, B. Moifo, and C. Kuaban, "Prevalence and determinants of extrapulmonary involvement in patients with pulmonary tuberculosis in a Sub-Saharan African country: A cross-sectional study," Infectious Diseases, vol. 45, no. 2, pp. 104-111, 2013.

[9] H. M. Peto, R. H. Pratt, T. A. Harrington, P. A. LoBue, and L. R. Armstrong, "Epidemiology of extrapulmonary tuberculosis in the United States, 1993-2006," Clinical Infectious Diseases, vol. 49, no. 9, pp. 1350-1357, 2009.

[10] A. M. Kipp, J. E. Stout, C. D. Hamilton, and A. Van Rie, "Extrapulmonary tuberculosis, human immunodeficiency virus, and foreign birth in North Carolina, 1993-2006," BMC Public Health, vol. 8, article no. 107, 2008.

[11] Y. Zenebe, B. Anagaw, W. Tesfay, T. Debebe, and B. Gelaw, "Smear positive extra pulmonary tuberculosis disease at University of Gondar Hospital, Northwest Ethiopia," BMC Research Notes, p. 21, 2013.

[12] A. Fanosie, B. Gelaw, B. Tessema, W. Tesfay, A. Admasu, and G. Yitayew, "Mycobacterium Tuberculosis complex and HIV coinfection among Extrapulmonary Tuberculosis suspected cases at the University of Gondar hospital, northwestern Ethiopia," PLoS ONE, vol. 11, no. 3, Article ID e0150646, 2016.

[13] L. R. Patel, J. A. Panchal, J. D. Pethani, S. D. Rathod, P. H. Patel, and P. D. Shah, "Screening of extrapulmonary tuberculosis samples by zeihl neelsen staining in patients presenting at tertiary care hospital ahmedabad," National Journal of Community Medicine, vol. 4, no. 1, pp. 165-167, 2013.

[14] U. Kingsley, A. Isaac, I. Ngozi, O. Chijioke, and I. Chika, "From DOTS to the Stop TB Strategy: DOTS coverage and trend of tuberculosis notification in Ebonyi, southeastern Nigeria, 1998 - 2009," Pan African Medical Journal, vol. 9, 2011.

[15] S. Chakravorty, M. K. Sen, and J. S. Tyagi, "Diagnosis of extrapulmonary tuberculosis by smear, culture, and PCR using universal sample processing technology," Journal of Clinical Microbiology, vol. 43, no. 9, pp. 4357-4362, 2005.

[16] L. E. Cuevas, N. Al-Sonboli, L. Lawson et al., "LED fluorescence microscopy for the diagnosis of pulmonary tuberculosis: a multi-country cross-sectional evaluation," PLoS Medicine, vol. 8, no. 7, Article ID e1001057, 2011.

[17] "Cepheid: Xpert MTB/RIF. Cepheid GeneXpertDx System Operator Manual, Cepheid 2012," http://www.cepheid.com/en/.

[18] S. Herath and C. Lewis, "Pulmonary involvement in patients presenting with extra-pulmonary tuberculosis: thinking beyond a normal chest x-ray," Journal of Primary Health Care, vol. 6, no. 1, pp. 64-68, 2014.

[19] A. Houston and D. C. Macallan, "Extrapulmonary tuberculosis," Medicine (United Kingdom), vol. 42, no. 1, pp. 18-22, 2014.

[20] A. K. Shrivastava, S. Brahmachari, P. Pathak, and et. al, "Clinicoepidemiologic profile of extra-pulmonary tuberculosis in centr India," International Journal of Medical Research and Review, vol. 3, no. 2, pp. 223-230, 2015.

[21] T. E. M. Abdallah, F. E. M. Toum, O. H. Bashir et al., "Epidemiology of extra pulmonary tuberculosis in Eastern Sudan," Asian Pacific Journal of Tropical Biomedicine, vol. 5, no. 6, pp. 505-508, 2015.

[22] V. Chander, S. K. Raina, A. K. Bhardwaj, A. Gupta, S. Kashyap, and A. Sood, "Clinico-epidemiological profile of extra pulmonary tuberculosis: A report from a high prevalence state of northern India," International Journal of Tropical Medicine, vol. 7, no. 3, pp. 117-120, 2012.

[23] T. Gomes, B. Reis-Santos, A. Bertolde, J. L. Johnson, L. W. Riley, and E. L. Maciel, "Epidemiology of extrapulmonary tuberculosis in Brazil: a hierarchical model," BMC Infectious Diseases, vol. 14, no. 1, article no. 9, 2014.

[24] A. Ong, J. Creasman, P. C. Hopewell et al., "A molecular epidemiological assessment of extrapulmonary tuberculosis in San Francisco," Clinical Infectious Diseases, vol. 38, no. 1, pp. 2531, 2004.

[25] H. Sohn, A. D. Aero, D. Menzies et al., "Xpert MTB/RIF testing in a low tuberculosis incidence, high-resource setting: limitations in accuracy and clinical impact," Clinical Infectious Diseases, vol. 58, no. 7, pp. 970-976, 2014. 
[26] M. Tadesse, D. Aragaw, L. Rigouts, and G. Abebe, "Increased detection of smear-negative pulmonary tuberculosis by GeneXpert MTB/RIF ${ }^{\circledR}$ assay after bleach concentration," International Journal of Mycobacteriology, vol. 5, no. 2, pp. 211-218, 2016.

[27] C. M. Denkinger, S. G. Schumacher, C. C. Boehme, N. Dendukuri, M. Pai, and K. R. Steingart, "Xpert MTB/RIF assay for the diagnosis of extrapulmonary tuberculosis: a systematic review and meta-analysis," European Respiratory Journal, vol. 44, no. 2, pp. 435-446, 2014.

[28] H. G. Batz, G. S. Cooke, and S. D. Reid, "Towards lab-free tuberculosis diagnosis," Treatment Action Group, the TB/HIV Working Group of the Stop TB Partnership, Imperial College, and the MSF Access Campaign, 2011.

[29] T. T. Balcha, E. Sturegård, N. Winqvist et al., "Intensified tuberculosis case-finding in HIV-positive adults managed at ethiopian health centers: diagnostic yield of xpert MTB/RIF compared with smear microscopy and liquid culture," PLoS ONE, vol. 9, no. 1, Article ID e85478, 2014.

[30] G. Lombardi, V. Di Gregori, N. Girometti, M. Tadolini, F. Bisognin, and P. Dal Monte, "Diagnosis of smear-negative tuberculosis is greatly improved by Xpert MTB/RIF," PLoS ONE, vol. 12, no. 4, Article ID e0176186., 2017.

[31] L. Maynard-Smith, N. Larke, J. A. Peters, and S. D. Lawn, "Diagnostic accuracy of the Xpert MTB/RIF assay for extrapulmonary and pulmonary tuberculosis when testing nonrespiratory samples: a systematic review," BMC Infectious Diseases, vol. 14, no. 1, article 709, 2014.

[32] T. Saad and A. S. Tirkey, "Association between pulmonary tuberculosis and smoking: a case control study," Indian Journal of Community Health (IJCH), vol. 25, no. 4, pp. 340-347, 2013.

[33] F. Biadglegne, B. Tessema, U. Sack, and A. C. Rodloff, "Drug resistance of Mycobacterium tuberculosis isolates from tuberculosis lymphadenitis patients in Ethiopia," Indian Journal of Medical Research, vol. 140, pp. 116-122, 2014.

[34] M. Agonafir, E. Lemma, D. Wolde-Meskel et al., "Phenotypic and genotypic analysis of MDR-TB in Ethiopia," International Journal of Tuberculosis and Lung Disease, vol. 14, pp. 1259-1265, 2010. 


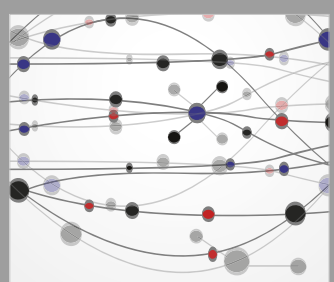

The Scientific World Journal
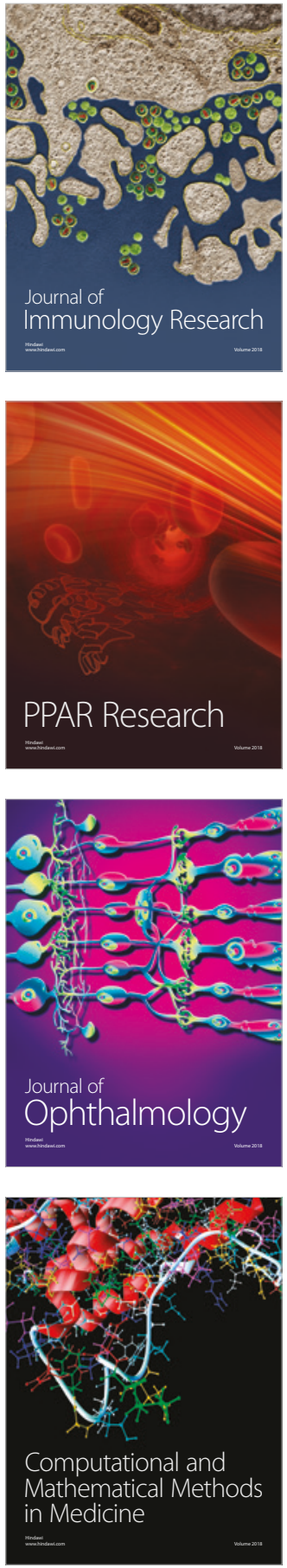

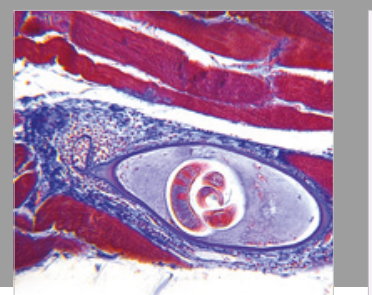

Gastroenterology Research and Practice

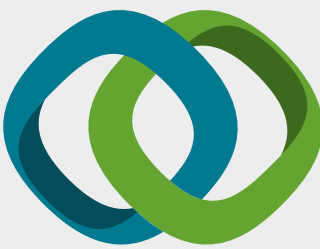

\section{Hindawi}

Submit your manuscripts at

www.hindawi.com
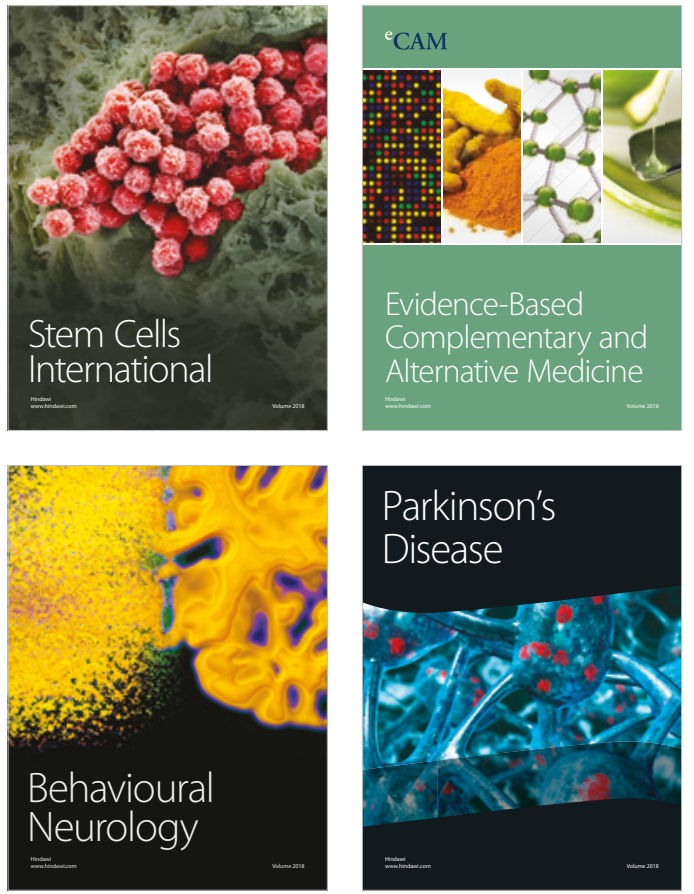

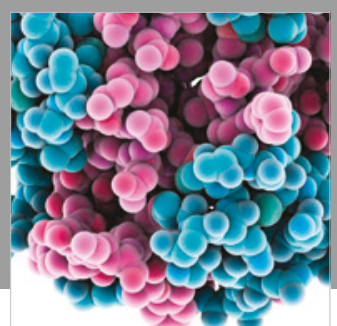

ournal of

Diabetes Research

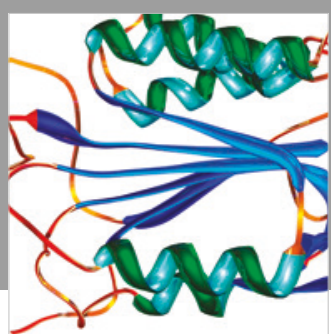

Disease Markers
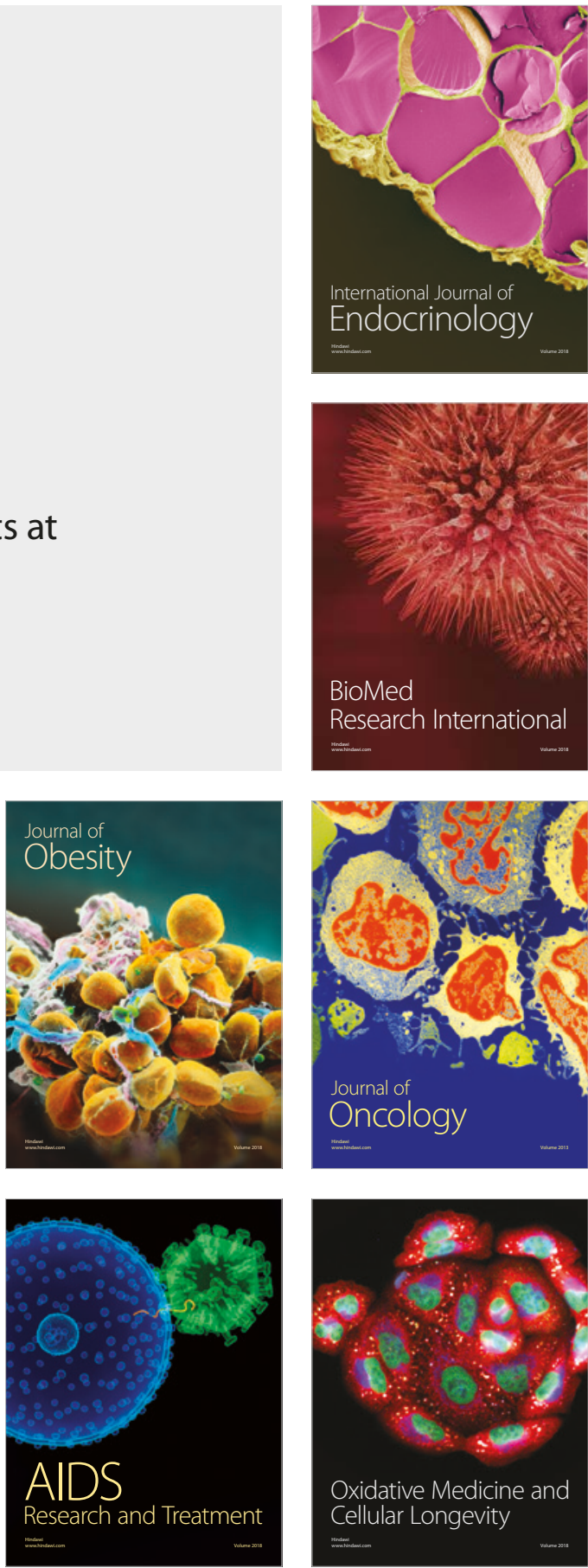